\title{
A produção de ladrilho e o ofício de ladrilhar: método de produção de ladrilhos do século XVIII aos nossos dias'
}

The production of tile and the craft of tiling: method of tile production from the 18th century to the present day

\author{
MÁRCIA LOPES LAMAS² \\ Universidade Federal Fluminense / Niterói, RJ, Brasil
}

\section{ORLANDO CELSO LONGO3}

Universidade Federal Fluminense / Niterói, RJ, Brasil

\section{VICENTE CUSTÓDIO DE SOUZA ${ }^{4}$}

Universidade Federal Fluminense / Niterói, RJ, Brasil

RESUMO: Com o objetivo de estudar o ladrilho hidráulico, em destaque na construção civil do século XIX e considerado patrimônio cultural pelo Iphan, o presente trabalho traça a trajetória histórica deste material. Embora as cartas patrimoniais recomendem ações de manutenção periódicas de conservação preventiva, há uma lacuna de registros sobre o ladrilho hidráulico, sobretudo no que tange a seu surgimento e a sua técnica de fabrico. Este artigo aponta o fabrico do ladrilho cerâmico como precursor do ladrilho hidráulico, debruçando-se sobre os motivos que levaram a tal transformação. Os resultados mostram que a produção dos ladrilhos hidráulicos foi recuperada na transição do século XVIII para o XIX, com novos significados e valores que atualizaram o sentido do uso do material, elevando-o a protagonista do ambiente para o qual é concebido. A fim de contribuir com o registro da gênese histórica do ladrilho hidráulico, este trabalho realiza também uma ampla revisão das publicações relevantes sobre o tema.

\begin{abstract}
1. Este trabalho foi financiado pela Coordenação de Aperfeiçoamento de Pessoal de Nível Superior (Capes) junto ao Programa de Pós-Graduação em Engenharia Civil da Universidade Federal Fluminense.

2. Bolsista do Programa de Pós-Graduação em Engenharia Civil da Universidade Federal Fluminense. E-mail: $<$ marciallamas@gmail.com>.

3. Professor do Departamento de Engenharia Civil da Universidade Federal Fluminense. Doutor em Engenharia de Transportes pela Universidade Federal do Rio de Janeiro. E-mail: <orlandolongo@gmail.com>.

4. Professor do Departamento de Engenharia Civil da Universidade Federal Fluminense. Pós-doutor pelo Laboratório Nacional de Engenharia Civil. E-mail: $<$ vcmdesouza@hotmail.com>.
\end{abstract}

PALAVRAS-CHAVE: Ladrilho. Revolução Industrial. Século XIX. Patrimônio. Cimento. 
5. Instituto do Patrimônio Histórico e Artístico Nacional (2004).
ABSTRACT: Aiming to study the hydraulic tile, the centerpiece in the nineteenth-century civil construction and considered a cultural heritage by Iphan, this research traces the historical trajectory of this material. Although the patrimonial charters recommend periodic maintenance actions of preventive conservation, there is a gap on the hydraulic tile records, mainly regarding its creation and its manufacture technique. This article points out the manufacture of ceramic tile as a precursor of the hydraulic tile, focusing on the reasons that led to such a transformation. The results show that the production of hydraulic tiles was brought back in the transition from the eighteenth to the nineteenth century, with new significations and values that updated the meaning of the material use, elevating it to a protagonist of the environment for which it is conceived. In order to contribute to the record of the historical genesis of the hydraulic tile, this study also carries out an extensive review of the relevant publications on the subject.

KEYWORDS: Tile. Industrial Revolution. Nineteenth century. Heritage. Cement.

\section{INTRODUÇÃO}

Em seu site, o Instituto do Patrimônio Histórico e Artístico Nacional (lphan), considera patrimônio histórico e cultural o "bem material, natural ou imóvel que possui significado e importância artística, cultural, religiosa, documental ou estética para a sociedade". 5 Na página, os ladrilhos hidráulicos são mencionados como representantes de patrimônio cultural a ser preservado, tanto do ponto de vista material quanto imaterial, uma vez que a produção artesanal deve ser resguardada e passada de geração a geração, mesmo que a tecnologia empregada nos processos avance. Dessa forma, o ladrilho é, até os dias de hoje, mais que um objeto para restauro ou paginação, indo além do simples fascínio pelo antigo e assumindo um valor sentimental, como lembrança nostálgica que traduz o poder contido em seu corpo ao revelar brasões familiares, armas, selos, casas de nobreza, castas clericais, preces ou trechos bíblicos, aguçando os sentidos pelo esplendor do conjunto, pela perpetuação e longevidade do material, que ostenta a durabilidade de ao menos um século.

Este trabalho visa resgatar e esclarecer o processo de produção e recuperação de ladrilhos, validando a ampliação do conhecimento técnico no decorrer da história do revestimento, investigando o contexto do aparecimento e 
difusão do ladrilho, teorizando e sistematizando dados relativos às técnicas de fabrico e estabelecendo uma hipótese teórica na linha de evolução do material. $\bigcirc$ principal objetivo é discernir como surge o ladrilho hidráulico no século XIX, estudando-o através do tempo e em sua nova identidade.

Para tanto, o material consultado incluiu bibliografia em meios primários (documentos, manuscritos, catálogos e impressos) e secundários (livros, artigos dissertações e teses), além de fontes iconográficas e orais (entrevistas e depoimentos), identificando na pesquisa uma escassez de material científico sobre o tema.

Essa falta de consistência bibliográfica, somada à crescente demanda pelo produto - a qual vulgariza o domínio da técnica de fabricação -, revela a necessidade de resgatar e registrar este conhecimento.

De modo geral, o que ocorre é uma lacuna de registros históricos no que se relaciona ao ladrilho hidráulico, sobretudo o seu surgimento no que tange à técnica de fabrico, um não sincronismo entre datas e eventos - consequência direta da bibliografia intrincada. Soma-se o comprometimento semântico da palavra "ladrilho" sob a ótica da pluralidade de significados, em que "ladrilho", "tijolo", "azulejo" e "telha", embora apresentem definições heterogêneas, são materiais incontestavelmente utilizados em operações de ladrilhamento. Nas fontes consultadas são inúmeros os casos de uso do termo "ladrilho" para referirse a diversos tipos de materiais:

Para o aspecto específico das terminologias dos materiais cerâmicos, de uma maneira geral, as línguas românicas e germânicas adotaram derivações das palavras existentes no latim, as quais se modificaram posteriormente conforme as regiões. Neste percurso, observa-se que as palavras-chaves que originam de modo geral das terminologias da Europa Ocidental fincam-se pelas raízes dos vocábulos latinos laterculus e tergula que, para o caso português, dão origem respectivamente a ladrilho, telha e tijolo. ${ }^{\circ}$

Na análise da terminologia, percebe-se um vínculo entre os vocábulos por padrões fonéticos, como as várias denominações para o tijolo romano later, que linguisticamente tem a mesma origem e técnica. Personalizado conforme a sua cozedura e tipo de fabrico, tal tijolo logicamente assumia vários formatos, sendo por isso autenticado pelo próprio fabricante, que nele gravava seu nome ou o nome da olaria. Laterculus era o nome que se dava aos tijolos e ladrilhos de pequenas dimensões, e que, por extensão, passou também a designar qualquer objeto de barro que tivesse o mesmo feitio:

Por isso, há que ter cuidado e muita atenção, porque os arqueólogos, nomeadamente os italianos, usam a classificação "laterculus" para todos os pedacinhos de barro que, sem saberem do que se trata, registram nos seus espólios e até nos inventários dos museus. Por 
7. Mesquita (2014).

8. Brancante (1981).

9. Durbin (2005; 2006).

10. Eames (1968; 1985, 1992).

11. Em 1835, Samuel Wright, um comerciante em Stoke-on-Trent, que se especializou em vender zaffer (um minério de cobalto utilizado por cerâmicas para fazer azuis intensos), experimentando reproduções medievais, se utiliza de moldes de gesso para a confecção dos ladrilhos. A patente consistia no método de produção de ladrilho por meio de um molde de gesso Paris previamente cortado com um padrão, definido em uma estrutura de metal com pregos e parafuso unindo os dois lados. Essa técnica melhora em muito a padronização das peças, mas não consegue resolver definitivamente os problemas que ocorrem em função das diferentes retrações da cerâmica durante a queima. "latericius" designava-se tudo aquilo que fosse construído com tijolos de barro grosseiro ou com ladrilhos de fraca qualidade. [...] As técnicas de construção dos romanos eram fiáveis e muito avançadas para o seu tempo, recorrendo muitas vezes à cal hidráulica, uma técnica que levamos quase mil anos para descobrir como se fazia?

Para encontrar um sentido ou definição que estabeleça um marco para a técnica do ladrilho, é necessário entender conceitualmente o material em estudo. Para isso, comparamos a palavra "ladrilho" com outros produtos cerâmicos de construção que apresentam uma polivalência de significados materiais - o azulejo, a telha, o tijolo - e que, efetivamente, substituem em alguns casos a terminologia de "ladrilho".

\section{A MATÉRIA-PRIMA DO LADRILHO, ANTECEDENTES DA TÉCNICA}

A história da cerâmica está totalmente ligada à história da humanidade e sua evolução, sendo a indústria cerâmica considerada por alguns estudiosos a mais antiga das indústrias. ${ }^{8} \mathrm{~A}$ escolha do período medieval como marco inicial para este estudo se justifica principalmente pelas técnicas de elaboração dos ladrilhos utilizadas no período, as quais se assemelham às usadas nas confecções atuais. Com base nessa semelhança, a fim de estabelecer a origem de técnicas ainda hoje utilizadas, buscamos metodologias e conceitos comuns à elaboração de revestimentos atual e daquele período. ${ }^{9}$

A confecção do ladrilho encáustico (Figura 1), ou telha encáustica, do século XII, foi uma atividade artesanal de pequena escala, em que o ladritho era elaborado a partir do recorte de uma porção de um bloco de argila plástica, em formato de placa, modelado em uma fôrma de madeira. $\bigcirc$ padrão ou figura existente na superfície não era resultado de uma pintura, mas do contraste de cores entre diferentes tipos de argilas utilizadas na mesma peça. Ladrilhos encáusticos são normalmente de duas cores, mas podem ser compostos por até seis cores in natura. ${ }^{10} \mathrm{O}$ maior desafio era reproduzir as técnicas medievais de combinação de argilas, que permitiam uma retração no processo de queima dos ladrilhos sem danos, já que muitas levas destes foram perdidas por problemas de fissura, esmaltação e retração.

No correr do século XIX, os arquitetos e fabricantes de ladrilhos precisaram de inspiração e entendimento das técnicas medievais de produção para atender a um mercado emergente, que demandava cada vez mais prédios públicos, e suprir a necessidade eclesiástica de restaurar suas igrejas e templos com a mesma beleza e qualidade dos originais. Uma vez que Samuel Wright ${ }^{11}$ tirou a patente 

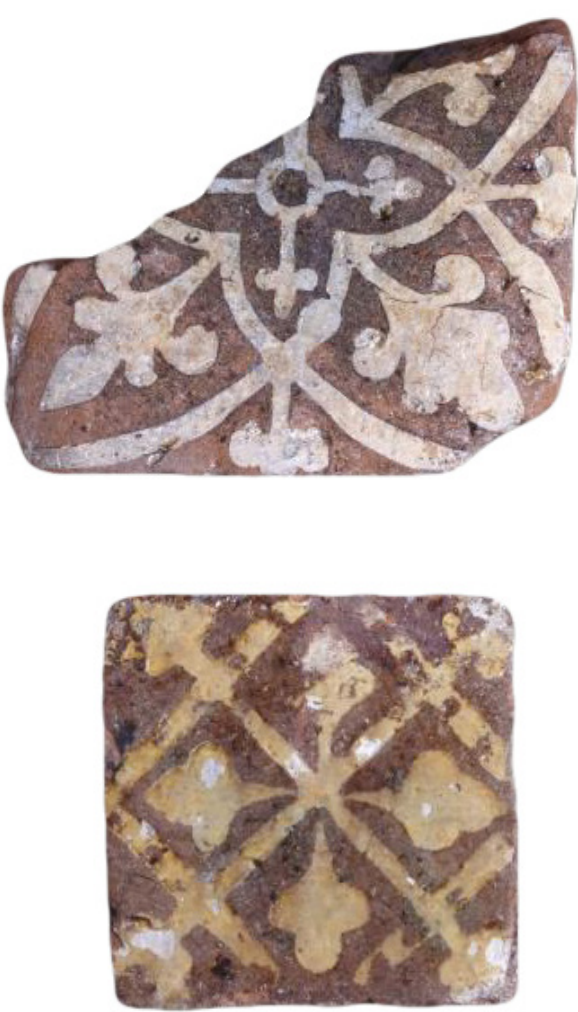
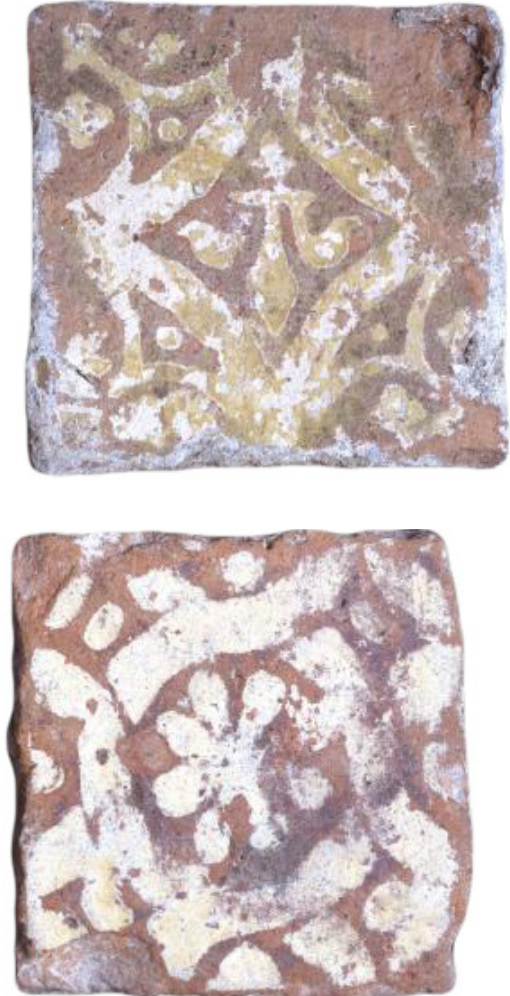

Figura 1 - Ladrilho de cerâmica do século XIV. Fonte: British Museum. ${ }^{12}$

para fazer ladrilhos embutidos em molde e estabeleceu um método para a produção em massa, empresários da indústria de revestimentos cerâmicos, como Herbert Minton, George e Arthur Maw, Henry Godwin e Jesse Carter, compartilharam da intenção de usar a ciência como base para a fabricação de um produto materialmente consistente, rápido de produzir e comerciável a um custo acessível. ${ }^{13}$ Evitando a natureza aleatória das tecnologias anteriores, que se baseavam na elaboração artesanal ao invés da produção da máquina, eles lançaram um catálogo com uma série de ladrilhos encáusticos projetados principalmente com base em padrões medievais. ${ }^{14}$

Com o progressivo desenvolvimento industrial, os revestimentos cerâmicos para paredes e pisos deixaram de ser privilégio de recintos religiosos e palácios, tornando-se acessíveis a todas as classes sociais. Passando às fachadas dos pequenos sobrados comerciais e residenciais, e até mesmo de casas térreas, eles trouxeram para as paredes externas o colorido e o luxo das paredes internas. Apesar de toda essa efervescência, as grandes perdas provocadas pelas diferentes contrações das argilas na queima dos ladrilhos e o alto custo de produção e distribuição permaneciam como entrave a um ainda maior crescimento da indústria. 
15. Durbin (2005).

16. Puggeg: continuamente virado e dobrado em um estado úmido (Durbin, 2005).

17. Darby (2014).

18. Laiton: moldura de metal fino em liga amarela composta principalmente de cobre e zinco. Também conhecido como divisor (Esquieu, 2013).
Herbert Minton, um dos principais fabricantes e comerciantes de ladrilhos em Stok-on-Trent, na Inglaterra, buscou aperfeiçoar o processo, trabalhando arduamente na solução do problema entre 1835 e 1840. A persistência de Minton em fazer ladrilhos encáusticos foi recompensada em 1841, com o convite para fazer as réplicas de ladrilhos medievais recentemente descobertos em Abbey Westminster para a Temple Church, em Londres, que precisava ser pavimentada. ${ }^{15}$

Em 1840, Richard Prosser apresenta uma nova patente, conhecida como "pó pressionado", em que o ladrilho, alterado pelo preparo da argila, passa a depender diretamente da qualidade desta e de seu método de preparação. Cada argila e os demais componentes eram pulverizados, medidos e misturados em estado puggeg, ${ }^{16}$ depois secos e passados por uma série de peneiras e deixados para maturar em caixas até estarem prontos para serem utilizados.

A técnica de Prosser permitiu que a produção atendesse a demanda comercial ao diminuir o tempo de produção do ladrilho, conforme descreve Sue M. Darby:

O método de argila seca foi o único que eliminou o período difícil de secagem exigido por ladrilhos e tijolos confeccionados por argila plástica. Como diz um inventor, "qualquer máquina que pode fazer tijolos ou telhas de barro em um estado parcialmente seco pode trabalhar ao longo de todo ou pelo menos a maior parte do inverno". ${ }^{17}$

No desenvolvimento de novas linhas de produção em massa, era comum que os fabricantes alterassem fórmulas de composição, variassem os ingredientes, modificassem o tamanho de matrizes e moldes, cozinhassem os ladrilhos em áreas diferentes do forno ou até mesmo queimassem todo o forno de forma diferente, imprimindo sua identidade ao produto. Dessa forma, em 1860, também o método Prosser experimentou variação em seu processo - que até então produzia ladrilhos lisos de três camadas de argila em pó -, passando a usar apenas duas camadas de pó, sendo a face frontal mais colorida, com a inclusão de uma moldura de metal fino conhecida como laiton, ${ }^{18}$ colocada dentro da matriz para permitir a separação das cores conforme a arte desejada.

O sistema consistia no preenchimento dos compartimentos da estrutura com uma pequena quantidade de pó de argila de cor diferente, vertida à mão em cada seção do molde para criar o projeto do ladrilho. A moldura era cuidadosamente removida, um volume de argila complementar acrescentado e todo o lote compactado sob enorme pressão - até quatro toneladas por polegada quadrada.

A técnica de pó pressionado criou a oportunidade para a produção de ladrilho em grande escala, revolucionando o mercado de pisos e revestimentos cerâmicos. Cada empresa tinha sua própria gama de cores e desenhos em uma variedade de tamanhos e formas geométricas, permitindo aos fabricantes desenvolver suas próprias 
faixas de cores e desenhos conforme o estilo de cada casa oleira. Os fabricantes de revestimentos cerâmicos do século XIX, portanto, possuíam o que era essencialmente um produto novo, produzido em massa e utilizado da melhor forma possível, tanto funcional como decorativamente.

Entre 1780 e 1829, as necessidades da indústria da construção estimularam a busca por compostos químicos que pudessem servir de matéria-prima para argamassas de revestimento externo. Foi em meados de 1830 que o inglês Joseph Aspdin patenteou - processo de fabricação de um ligante que resultava da mistura, calcinada em proporções certas e definidas, de calcário e argila, conhecido mundialmente até hoje. $\bigcirc$ resultado foi um pó que, por apresentar cor e características semelhantes às de uma pedra abundante na llha de Portland, foi denominado "cimento Portland". ${ }^{19}$

Em todo o mundo, a utilização e comercialização do cimento cresceu então de forma gradativa, e seu uso inicial como argamassa colante assumiu novo status, como revestimento, passando a fazer parte da composição de estruturas e fachadas de prédios, monumentos e outros equipamentos, como pontes e faróis. No Brasil, essa mistura de pedras calcárias e argila começou a ser fabricada por volta de 1888, em Sorocaba, pelo comendador Antônio Proost Rodovalho, e posteriormente, em 1924, foi instalada a Companhia Brasileira de Cimento Portland, no bairro de Perus, na cidade de São Paulo. ${ }^{20}$

Os fabricantes de revestimentos cerâmicos não demoraram a reconhecer os atributos positivos do cimento Portland como fixador das peças cerâmicas: dentre outras vantagens, o novo ligante não provocava manchas tão facilmente como a argamassa de cal tradicional.

Frutos dessas mudanças, duas empresas produtoras de ladrilho se estabeleceram a partir de 1859 no sul da França. Segundo Esquieu, foi em Viviers, uma pequena cidade no Vale do Rhône, onde a presença do cimento Lafarge Pavin é reconhecida, que Etienne Larmande, empreiteiro de obras públicas, registrou em 1860 uma patente de fabricação de uma cal hidráulica que revolucionaria a produção de ladrilho.

"A cal hidráulica, misturada em determinadas proporções com argila calcinada, areia e água, produz um material tão duro como pedra, sem a necessidade de qualquer cozedura". Deve-se preparar a massa e a verter em moldes, que devem dar ao produto as formas desejadas quando colocados sob grande pressão. [...] Quando a pressão é feita, as peças devem ser deixadas para secar em qualquer ar, seco ou molhado. $\bigcirc$ que pode dar a cor desejada é a mistura na preparação da massa com pigmentos, que deve produzir os mais variados desenhos. ${ }^{21}$
19. Associação Brasileira de Cimento Portland (2013).

20. Idem.

21. Esquieu (2013, p. 22). No original: " La chaux hydraulique ou mélangée dans de certaines proportions à l'argile calcinée [c'est l'équivalent de la pouzzolane] fait une matière aussi dure que la pierre sans qu'il soit besoin d'aucune cuisson ". Il convient de préparer les matières " dans des moules qui doivent donner au produit les formes désirées, de les placer sous une forte pression [...]. L'osque la pression est opérée, on sort les pièces qu'on laisse dessécher à l'air sec ou humide de préférence. On $\mathrm{z}$ des briques, carreaux etc. activés, propres, nets, durs, inaltérables, auxquels on peut donner la couleur que l'on désire en mêlant dans la préparation des matières ou pigments qui doivent la produire, pouvant former les dessins les plus varies ”". $\bigcirc$ processo pouco ou nada se diferenciava do utilizado na indústria cerâmica da época para a produção de ladrilho. 
22. Esquieu (2013, p. 25).

23. Disponível em: <https:// bit.ly/2s8UEGM $>$. Acesso em: 24 maio 2018
A cal hidráulica ganha destaque e é amplamente divulgada nas exposições internacionais como o ladrilho que dispensa cozimento. $\bigcirc$ Catálogo Geral da Exposição Universal de Paris, em 1867, afirma que M. Damon e Rouset de Viviers (Ardèche) expuseram "tijolos, telhas, ladrilhos e materiais de construção em argamassa de cal, com decoração policromada incorporada na massa". ${ }^{22}$

Na verdade, a ideia da criação de ladrilhos coloridos com padrões incorporados no corpo da peça parece estar em voga no momento e, como aconteceu com outros produtos, como o concreto armado, muitos inventos surgiram para esse processo ao mesmo tempo. A proliferação de catálogos com vários modelos (Figura 2) reflete essa paixão pelo ladrilho. Interessados em artes decorativas, os fabricantes propõem modelos de acordo com os gostos da época; assim, as curvas e os motivos vegetais, característicos do art nouveau que se desenvolve a partir do início dos anos 1890, são encontrados em ladrilhos que agora adornam as paredes das casas.

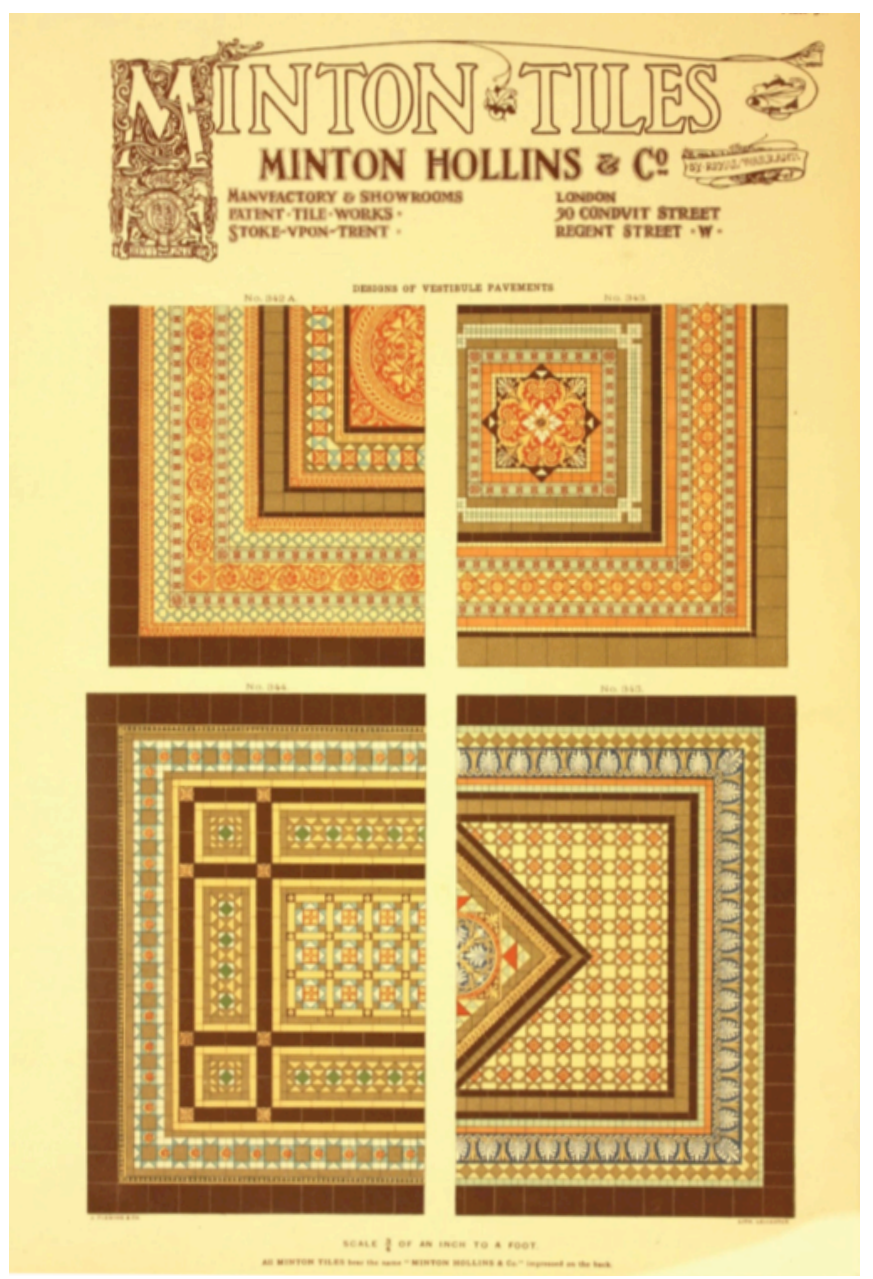

Figura 2 - Catálogo Minton Hollins \& Co., Stoke Upon-Trent, Inglaterra, 1905. Fonte: Internet Archive. ${ }^{23}$ 
Possivelmente, a dificuldade em gerar material científico sobre o tema esteja diretamente ligada ao caráter intimista que sempre predomina na produção dos ladrilhos hidráulicos, uma vez que se trata de um processo artesanal de fabricação. Isso fica evidente diante do grande sigilo mantido pelos fabricantes, em sua maioria membros da mesma família, que comumente dá seu nome ao produto e é detentora dos detalhes da constituição da matéria-prima e do processo de produção. ${ }^{24}$

Uma das maiores evidências da origem do ladrilho hidráulico está na forma como o mosaico é executado. Se, por um lado, a construção deste se dá pela união de fragmentos multicoloridos seguindo um desenho pré-concebido, o ladrilho hidráulico se desenvolve sob a mesma linguagem, com o desenho de cada peça definido segundo um molde metálico, o qual é preenchido com caldas de diferentes cores, resultando em desenhos multicoloridos. Ambos os processos de produção exigem procedimentos meticulosos de seus operadores.

O ladrilho hidráulico é conhecido como uma placa utilizada em pisos e revestimentos, usualmente constituída por três partes: o tardoz, ${ }^{25}$ a camada intermediária e a camada pigmentada. Esse revestimento recebe o nome de ladrilho hidráulico pelo fato de ser apenas molhado, sem processo de queima. ${ }^{26}$

tardoz, ou "mescla", como é nomeada pelos operários do setor, constitui-se em um corpo em argamassa de cimento Portland e pó de pedra; a camada intermediária, ou "secante", é constituída por cimento Portland, pó de pedra e areia lavada de rio; e a camada pigmentada é formada pela mistura de cimento Portland branco estrutural, pó de mármore e pigmentos. ${ }^{27}$

Ao contrário do que ocorre com muitas outras produções de caráter artesanal, que sofreram processos de decadência e desuso, o ladrilho, de certa forma, permaneceu inalterado até a contemporaneidade, tanto em relação ao processo de produção, quanto ao aspecto e características finais do produto. As mudanças que ocorreram estão relacionadas mais com o comprometimento de cada fabricante em se utilizar de matérias-primas, como o cimento, a areia e os óxidos metálicos de qualidade, o que pode interferir na aparência e na durabilidade das peças.

Carvalho apresenta um relato do mestre-artesão de uma fábrica de Corumbá, Mato Grosso do Sul, a respeito dos materiais:

A coisa mudou muito. Depois que foi caindo o ladrilho, veio a decadência dos materiais. Antigamente, a tinta era importada, mais forte, usava mais água. Era óxido de ferro. O tempo foi passando, as coisas foram sumindo da praça. $\bigcirc$ óleo para limpar as fôrmas também. O melhor era importado, próprio para o ladrilho. Não se faz mais. Era trazido de São Paulo há 40 anos. ${ }^{28}$
25. Tardoz (ou mescla) se refere à face do ladrilho que fica em contato com a argamassa.

26. Fábrica de Mosaicos (2014).

27. Segurado (1959).

28. Carvalho (2008, p. 21). 
que caracteriza a produção dos ladrilhos hidráulicos como artesanais, apesar da possibilidade da fabricação em série, é o fato de um único ladrilheiro operar o processo de produção do início ao fim. Esse contato direto com o produto final é uma condição para a boa consumação de seu trabalho e até mesmo para a correção de pequenas imperfeições nas peças. Cada ladrilho tem um caráter singular, guardando na textura e na coloração detalhes sutis impressos pelo ladrilheiro em seu fazer - frisando-se que as peças são sempre feitas uma a uma, e em muitos casos trazem a identificação do artesão ou da fábrica registrada em seu tardoz.

A fabricação dos ladrilhos hidráulicos artísticos continua obedecendo aos métodos de cem anos atrás. Eles são colocados em uma fôrma de ferro, com moldes dos desenhos desenvolvidos em latão. A durabilidade de um molde depende do cuidado que se tem e do material com o qual ele é feito. Os moldes antigos, que têm mais de cem anos, são muito mais resistentes que os novos, porque são feitos de ferro ou de bronze, e os atuais são de latão. Nesses moldes é vertida uma mistura composta por pó de mármore, cimento branco e óxido de ferro. É o óxido de ferro que determina as cores das peças. As fórmulas da cor variam não só em função do pigmento, mas do cimento (branco ou cinza), do minério, que é o pó de mármore, do quartzo e dos demais pigmentos. A mistura disso tudo é que dá a tonalidade desejada. ${ }^{29}$

À medida que aumenta a paleta de cores na composição, eleva-se também o custo, dada a exigência de artesãos mais experientes e mais bem remunerados, além de maior tempo para fabricação. Nessa fase, o conhecimento do artesão torna-se fundamental, pois a pressão sobre o molde é feita manualmente, determinando sua perfeição e igualdade.

Todos os processos descritos se servem de matérias-primas e ferramentas facilmente encontradas no mercado, de uso corrente em várias atividades. Também são utilizadas ferramentas corriqueiras, como carrinhos de mão, pás, peneiras, baldes, pequenas latas e conchas para lançamento de caldas para coloração do ladrilho, além de uma prensa - composta de braço giratório, eixo e cabeçote -, montada sobre uma mesa ou bancada de concreto, em cuja superfície se acopla uma espécie de chapa ou prato, em que se destacam trilhas ou escorregadeiras de metal, que em algumas prensas são em forma de cruz, por onde as fôrmas do ladrilho deslizam no processo de montagem das peças. Na sequência, retira-se o molde, as peças ficam em repouso por doze horas, são mergulhadas em tanques de água por duas horas e por fim são enviadas para secagem natural, sem uso de fornos ou estufas, por um período de quinze dias.

Três fases conduzem a técnica de fabrico do ladrilho hidráulico: (1) fase preliminar - preparação das massas (camadas); (2) elaboração do ladrilho e 
(3) a cura. A preparação das massas é uma atividade preliminar à elaboração do ladrilho, porém fundamental para sua fabricação. Cada massa tem formulação própria, conforme sua finalidade, e é preparada de forma independente pelos serventes ou ladrilheiro aprendizes.

Cada uma das três camadas do ladrilho (Figura 3) corresponde a uma massa de composição distinta. A face aparente (camada superior) é constituída de cimento Portland (branco ou cinza), mistura de dolomita e quartzo (pó de mármore), denominada "talco", pigmento (corante) e água para diluir até que a massa se torne líquida. A camada intermediária é composta de quartzo (calcita) e cimento Portland (cinza). Esta camada é denominada "secante", pois tem função de absorver o excesso de água da face aparente (camada superior). Já a camada inferior é feita de argamassa "comum" - quartzo (areia) e cimento Portland (cinza) hidratados. Esta camada é fixada no contrapiso. Por este motivo, deve ter uma textura áspera, que facilite a aderência.

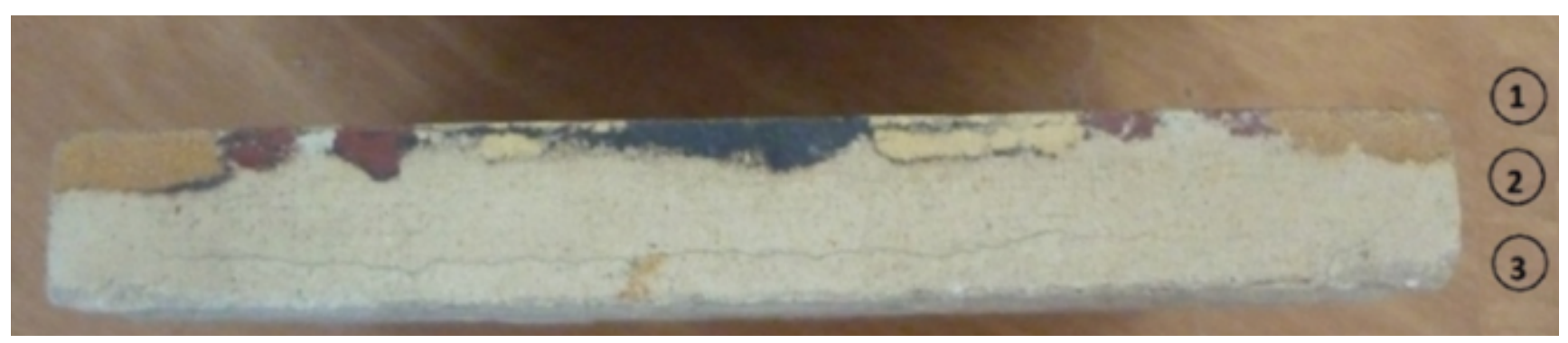

Figura 3 - Vista lateral de ladrilho hidráulico do Palácio da Justiça Federal no Rio de Janeiro (2010). Fonte: Arquivo pessoal.

Todo o processo começa com o molde (Figura 4), que forma a composição, o desenho. Há moldes simples e complexos, que exigem a motricidade fina do artesão. $O$ molde é fixado em esquadro de ferro, limpo e untado com uma mistura de óleo e querosene. $\bigcirc$ artesão preenche com cores as canaletas - que podem ter um conezinho onde o pigmento é derramado, facilitando o escoamento - e, quanto mais sofisticado o molde, maior a habilidade necessária.

Em seguida, a fôrma é retirada, e a umidade em excesso é absorvida por uma pequena porção de pó secante. Depois, é acrescentada a argamassa, base do ladrilho, nivelada pelo artesão com uma espátula ou com as próprias mãos e depois mandada para a prensa. $\bigcirc$ ladrilho é prensado com um ou dois movimentos. A observação e a prática dão a medida da força desse impulso, que deve ser perfeito e igual. Essa intensidade e tempo corretos são empíricos e equivalem ao "ponto de cozimento" nas artes culinárias. 

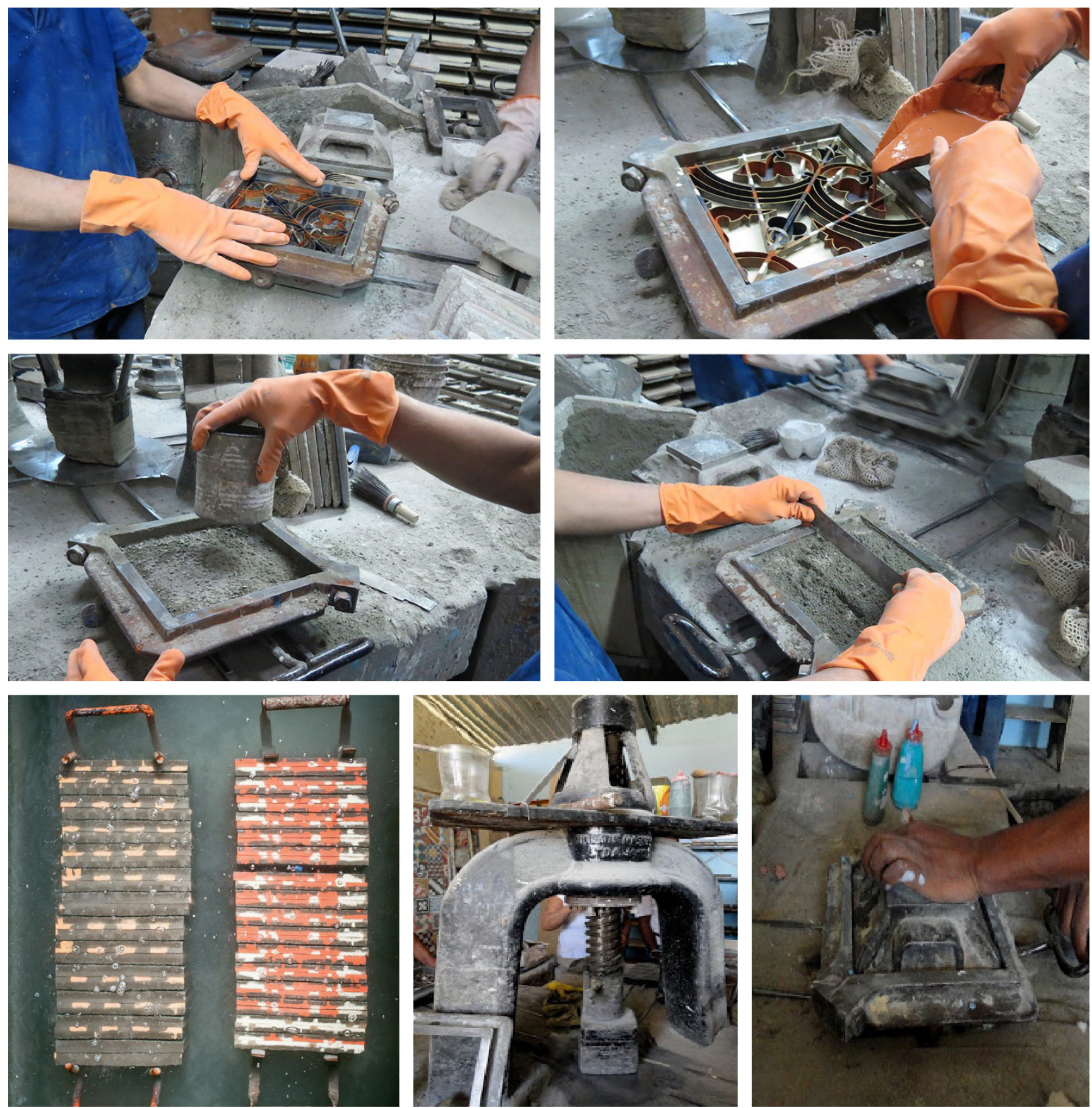

Figura 4 - Fabricação de ladrilho hidráulico na Fábrica de Ladrilho. Fonte: Arquivo pessoal. 
Um tampão de ferro comprime, na prensa, as três camadas que ficarão amalgamadas, proporcionando enorme resistência à peça. Quando o ladrilho está pronto, fica uma noite na prateleira para criar alguma solidez, podendo depois ser manipulado. Somente então é colocado em imersão na água. $\bigcirc$ artesão olha o aspecto do ladrilho e sabe quando absorveu a água necessária. Isso se dá em mais ou menos duas horas. Segue-se o escoamento da água e a secagem em prateleiras ventiladas.

\section{O OFÍCIO DE LADRILHAR}

A técnica de produção do ladrilho hidráulico se estabeleceu pelo "aprender fazendo" e assim permaneceu, como processo de transmissão dos saberes de pais para filhos e de mestres para aprendizes, como nos relata Silva:

Naquela ocasião se precisasse de um ladrilheiro o chefe falava com os funcionários e eles levavam conhecidos que entravam como aprendizes sem saber nada e aprendiam lá. $\bigcirc$ chefe da oficina, um ladrilheiro que trabalhava lá há muitos anos que ia ensinando. Eram mais de quarenta ladrilheiros que foram treinados lá. Eu me lembro que o senhor João levava o filho para a fábrica, o Vanir. Naquela ocasião, ele tinha uns doze anos, e aprendeu fazer os ladrilhos com o seu pai. ${ }^{30}$

ofício de ladrilhador pode ser dividido em categorias, conforme as diferentes atribuições na produção do ladrilho hidráulico. $\bigcirc$ modelista é quem faz a ferramenta e o molde, sendo necessárias habilidades artísticas para reproduzir o design proposto. Já o tinteiro é quem faz a pesquisa de tinta e desenvolve a cor, além da preparação das argamassas básicas e do cimento. O ladrilheiro, por sua vez, é o artesão que produz a peça.

Um ladrilheiro inicia o treinamento fazendo uma peça de calçada, pois é a mais fácil de ser produzida; passando a um nível superior, começa a trabalhar com ladrilho liso, de uma cor só; depois, passa a fazer o decorado, que é mais técnico e exige uma expertise que só os artistas gabaritados têm. Para se fazer uma peça de qualidade e com durabilidade, o profissional precisa de, no mínimo, cinco anos de treinamento. Os ladrilheiros mais antigos conhecem as especificidades de cada molde. ${ }^{31}$

Cada molde tem um jeito diferente para se fabricar o ladrilho, que varia conforme a quantidade da água, de cada tinta e da areia usada na mistura. Um ladrilho hidráulico leva de um a cinco minutos, no máximo, para ser fabricado. Não 
32. Catoia (2007)

33. Pesavento (1997).

34. Reis Filho (1978, p. 159).

35. Costa (2001). pode ultrapassar esse tempo no processo de confecção e desmolde, sob o risco da peça não se soltar e ser perdida, variando conforme a expertise de cada mestre ladrilhador a quantidade de ladrilhos produzidos por hora trabalhada. Em empresas de ladrilhos, a média diária de produção por pessoa não passa de 20 m², número justificado pela mão de obra artesanal. ${ }^{32}$

\section{O LADRILHO NO CENÁRIO NACIONAL}

A Revolução Industrial no século XIX propiciou o desenvolvimento econômico do mundo contemporâneo, transformando qualitativamente os processos produtivos, provocando o aparecimento da grande indústria e de novos produtos, a expansão do comércio mundial, da burguesia industrial e de novas doutrinas sociais e econômicas. As exposições universais, características desse período, tinham como principal objetivo instruir sobre a vida moderna da sociedade industrial, ensinando à massa um novo modelo de mundo. ${ }^{33}$

Conforme Reis Filho, o Brasil não fica indiferente a todas essas mudanças, e a preocupação higienista, também característica desse momento, torna-se mais um fator do sucesso do revestimento em pisos e paredes. Os arquitetos e engenheiros da época, ainda que dependendo amplamente de materiais importados, "dominavam com eficiência as técnicas e eram capazes de atender às exigências mais complexas de estruturas e acabamentos, que thes eram impostas por uma arquitetura em rápida evolução" ${ }^{34}$

Costa nos relata que estes profissionais tentavam aplicar as novas soluções construtivas tendo em vista as técnicas renovadas, os materiais e a tecnologia de construção da Revolução Industrial - de um lado, a evolução da ciência e da tecnologia europeia e a consequente necessidade de encontrar mercados consumidores para seus produtos; do outro, as condições econômicas, sociais e políticas que dificultavam a utilização dos fatores de produção, além da expansão colonial e das áreas de influência dos europeus. ${ }^{35}$

Os ladrilhos importados para o Brasil vinham de Portugal, da França e da Bélgica, e no final do século XIX os segredos das técnicas de manufatura do ladrilho foram passados aos imigrantes residentes no Brasil. A partir de então, foram instaladas aqui as primeiras fábricas.

Diversos são os estudos de casos em que a fabricação do ladrilho hidráulico se mistura ao desenvolvimento de grandes cidades no Brasil. Assim nos relata Silva, que contextualiza a inserção do ladrilho hidráulico na cidade de São Luís, acrescendo 
em sua pesquisa uma análise visual do revestimento em algumas edificações remanescentes e apontando que algumas fábricas que se estabeleceram em São 37. Krüger (2014). Paulo e Pelotas (RS) no início do século XX ainda permanecem em atividade. ${ }^{36}$

Em Pelotas, como reporta Krüger, a Fábrica de Mosaicos de Pelotas foi 38. Catoia (2007). fundada em 1914, em meio à efervescência econômica da cidade, dividindo o mercado com outras dezesseis fábricas de ladrilhos hidráulicos. ${ }^{37} \mathrm{~A}$ indústria do charque, estabelecida no final do século XVIII na região, foi fator desencadeante para o crescimento da cidade, transformando-a em núcleo de circulação de riquezas. Essa condição privilegiada permitiu que a cidade tivesse um planejamento urbano e uma arquitetura especial, criados por arquitetos e artistas que vinham da Europa trazidos pelos ricos charqueadores. $\bigcirc$ resultado está expresso em inúmeras obras que constituem, até hoje, uma paisagem urbana diferenciada, destacada pelo requinte e a sofisticação das técnicas e dos materiais construtivos utilizados, entre eles o ladrilho hidráulico.

Catoia destaca que o ladrilho hidráulico chegou a São Paulo no início do século XX e pode ser visto em muitos prédios da cidade. ${ }^{38}$ Embora tenha sido marcada por uma relativa inexpressividade, seja do ponto de vista político ou econômico, durante os primeiros três séculos desde sua fundação, São Paulo destacou-se em diversos momentos como cidade comercial e de composição heterogênea característica que a acompanhará em toda a sua história, atingindo seu ápice após o espetacular crescimento demográfico e econômico advindo do ciclo do café e da industrialização, que elevariam São Paulo ao posto de maior cidade do país, com diversos edifícios públicos: Theatro Municipal, Theatro São Pedro, Casa da Marquesa de Santos, Mosteiro de São Bento, Bolsa Oficial do Café, em Santos, Paróquia Nossa Senhora do Brasil e Palacete Conde de Sarzedas, dentre outros.

Melo e Ribeiro destacam o ladrilho hidráulico como elemento expressivo e característico do período eclético na cidade do Rio de Janeiro, aplicado em diversos edifícios públicos e privados. ${ }^{39}$ Com a Proclamação da República, nas últimas décadas do século XIX e início do XX, o Rio de Janeiro enfrentava graves problemas sociais, advindos do crescimento rápido e desordenado e da tomada de medidas impopulares, como as reestruturações do centro, executadas pelo engenheiro Pereira Passos, e as várias reformas urbanas e sanitárias que modificaram a imagem da então capital da República. Data desse período a abertura do Museu Nacional de Belas Artes, do Museu Histórico Nacional, do prédio do Iphan, da Fundação Oswaldo Cruz, do Palácio do Catete, do Museu Histórico Natural e do Museu Naval Oceanográfico.

Em Corumbá (MS), o ladrilho chegou no início do século XX, com a grande movimentação das navegações. $\bigcirc$ porto fluvial da cidade era o terceiro maior da 
40. Oficina (2011).

41. Associação Brasileira de Normas Técnicas (2013).
América Latina e movimentava pelos vapores da rota Europa-Brasil o comércio de peles, de charque e de outras riquezas da região. Em Mato Grosso, o pioneiro na arte de confeccionar ladrilhos hidráulicos foi Francisco Giovani Macchi, italiano da cidade de Lucca que aprendeu o ofício em sua terra natal e migrou para Cuiabá logo nos primeiros anos do século XX. Sua arte conquistou Corumbá, que na época vivia um apogeu econômico. Magníficos exemplos de sua arte podem ser vistos em boa parte das construções do casario do Porto e em muitas residências do centro da cidade. ${ }^{40}$

\section{CARACTERÍSTICAS TÉCNICAS}

A norma de ladrilho hidráulico vigente no Brasil é a NBR 9.457 de março de 2013, da Associação Brasileira de Normas Técnicas (ABNT), a qual estabelece as características técnicas dos ladrilhos, que devem ser comprovadas e controladas por testes de laboratórios. ${ }^{41}$ Para os efeitos desta norma, aplicam-se os seguintes termos e definições: ladrilho hidráulico e placa cimentícia paralelepipédica lque tem a forma de um paralelepípedo) de dupla camada, executada por prensagem, com a superfície exposta ao tráfego, lisa ou em baixo-relevo. A argamassa utilizada nas peças deve ser constituída de cimento Portland, agregados e água, sendo permitido o uso de aditivos e pigmentos, especificados conforme as determinações a seguir:

(1) o cimento Portland pode ser de qualquer tipo e classe, devendo atender às normas ABNT NBR 5.732, 5.733, 5.735, 5.736, 11.578 e 12.989;

(2) os agregados podem ser naturais, industriais ou reciclados, atendendo à ABNT NBR 7.211 ou às normas pertinentes;

(3) a água de amassamento deve atender à ABNT NBR 15.900-1 ;

(4) os aditivos devem atender à ABNT NBR 11.768 ;

(5) os pigmentos devem ser de base inorgânica e atender à ASTM C979/C979 M.

A unidade de compra das peças deve ser o metro quadrado $\left(\mathrm{m}^{2}\right)$, devendo-se especificar o número de peças por metro quadrado.

Os ladrilhos hidráulicos podem ser produzidos em diversas dimensões, respeitando-se o paralelismo entre as superfícies opostas. As dimensões e tolerâncias das peças devem atender aos seguintes critérios: 
(1) comprimento nominal máximo de 400 mm;

(2) largura nominal mínima de $100 \mathrm{~mm}$;

(3) espessura nominal mínima de 18 mm;

(4) tolerâncias dimensionais de espessura nominal entre 18 e 20 mm têm tolerância (+-3) para comprimento, (+-3) para largura e (+-1) para espessura; quando a espessura nominal for menor que $20 \mathrm{~mm}$ a tolerância passa a (+-3) para comprimento, (+-3) para largura e (+-2) para espessura.

A resistência mecânica das peças cimentícias, na condição de assentadas sobre a camada de apoio, deve ter flexão maior ou igual a 3,5 MPa. Estas propriedades devem ser verificadas de acordo com a ABNT NBR 13.818, com resultados superando os limites mínimos.

De acordo com o manual da Associação Brasileira de Cimento Portland, ladrilho hidráulico é uma placa de concreto de alta resistência ao desgaste para acabamentos de paredes e pisos internos e externos, contendo uma superfície com textura lisa ou em relevo, colorida ou não, de formato quadrado, retangular ou outra forma geométrica definida. ${ }^{42}$ Sua principal característica é a alta resistência a zonas de tráfego intenso, aliando características antiderrapantes e de alta resistência à abrasão, o que o torna indicado para calçadas, passeios públicos, praças, garagens, estacionamentos, rampas para automóveis, ambientes internos, bordas de piscinas etc., oferecendo segurança para as pessoas mesmo quando molhados.

A calçada de ladrilho hidráulico para ambientes externos deve levar em consideração aspectos de uso como abrasão, tráfego de pedestres, cadeirantes e intempéries. Os itens necessários para garantir a acessibilidade devem ser considerados durante a fase de projeto. Estes itens incluem inclinações máximas, rolamento do piso, utilização de pisos táteis, rampas etc. ${ }^{43}$

\section{CONCLUSÃO}

A utilização e comercialização do cimento cresceu de forma gradativa em todo o mundo; seu uso inicial como argamassa colante assumiu novo status como revestimento, passando a fazer parte da composição das estruturas e das fachadas de prédios, monumentos e outros equipamentos, como pontes e faróis. A partir daí grandes construções da nobreza francesa do século XIX, assim como da Espanha, da Itália e da Bélgica, passaram a utilizar este tipo de revestimento para compor 
sua arquitetura. No Brasil, como na Europa, os ladrilhos eram criados para decorar e revestir os pisos e paredes, expressando arte e religiosidade e sendo símbolo de status e modernidade.

A Revolução Industrial propiciou o desenvolvimento econômico do mundo contemporâneo, transformando qualitativamente os processos produtivos, provocando o aparecimento da grande indústria, de novos produtos, da expansão do comércio mundial, da burguesia industrial e de novas doutrinas sociais e econômicas. Foi nesse panorama de constantes mudanças que o ladrilho como conhecemos hoje surgiu e se firmou em um novo, elegante e refinado estilo, sobretudo com o modo de viver da sociedade burguesa, especialmente ligado à arte decorativa, quer seja ela de natureza interior ou exterior. Os artistas daquele final de século, sentindo que o vertiginoso desenvolvimento industrial facilitava a produção de obras em série, procuraram, por meio de uma herança de origem romântica, criar uma forma artística espontânea e original, que também satisfizesse à necessidade de expressão individual e ao desejo pessoal, mantendo o caráter individual e personalizado de cada trabalho.

Entender o fascínio com que o antigo contamina o imaginário coletivo talvez possibilite entender porque o ladrilho hidráulico atravessa o tempo. $\bigcirc$ fascínio que as coisas antigas exercem sobre os indivíduos pode ser um sentimento construído culturalmente ou resultado da tentativa de compreensão do "estar no mundo", ou ainda eco de manifestações dos primórdios da existência humana pela identificação com o lugar, a demarcação de territórios e a certificação das conquistas alcançadas. Dentro dessa perspectiva, os vestígios deixados pelo passado servem de estímulo à nossa imaginação, resgatando um fato do passado para a sua compreensão no presente.

Pensar na permanência do ladrilho hidráulico nas construções ou em nosso imaginário induz a reflexão do valor desse objeto que atravessou os tempos e sobreviveu às transformações ocorridas na sociedade, sobrevivendo aos novos valores atribuídos ao lugar e às relações com as novas formas de compor espaços e tecnologias. A tradição é dependente da memória e reluta contra a transformação.

A questão da significância do ladrilho hidráulico respalda-se nos valores que o objeto carrega e nos atributos estéticos, históricos, científicos, sociais e espirituais intrínsecos à memória coletiva a que pertencem ou pela qual foram declarados bem culturais a ser preservados. As atividades de conservação e restauro de ladrilhos têm como linha de conduta os princípios da garantia da integridade e da autenticidade dos componentes construtivos das edificações onde se encontram inseridos. A adoção dessa atitude tem fundamento nos compromissos firmados por entidades e especialistas para a conservação do patrimônio. 
Desse modo, partindo de todos os conceitos e ideias abordadas, os ladrilhos hidráulicos alcançam status de arte. $O$ desvelamento do conjunto de meios e procedimentos, através de uma técnica certificada através do tempo, pela qual é possível obter uma finalidade prática, torna possível reconhecer a produção de ladrilhos como uma arte a ser defendida, um patrimônio visual de cunho material e imaterial que está sendo esquecido e substituído por peças que não trazem o mesmo valor cultural e histórico. 


\section{REFERÊNCIAS}

ASSOCIAÇÃO BRASILEIRA DE CIMENTO PORTLAND. Uma breve história do cimento Portland. 2013. Disponível em: <https://bit.ly/2ItPziI>. Acesso em: 22 maio 2018.

. Manual de ladrilho hidráulico: passeio público. São Paulo: ABCP, 2010. Disponível em: <https://bit.ly/2KNNlfr>. Acesso em: 22 maio 2018.

ASSOCIAÇÃO BRASILEIRA DE NORMAS TÉCNICAS. NBR 9457: ladrilhos hidráulicos para pavimentação: especificações e métodos de ensaio. Rio de Janeiro, 2013.

BECKER Ângela Weingärtner; VUOLO, Cândida Maria. O mago dos ladrilhos hidráulicos. Pós-, São Paulo, v. 16, n. 25, p. 27-32, jun. 2009.

BRANCANTE, Eldino F. O Brasil e a cerâmica antiga. São Paulo: [s.n.], 1981.

CARVALHO, Luciana. Ladrilhos hidráulicos de Corumbá. Rio de Janeiro: Iphan; CNFCP, 2008.

CASABO, Juan. Fabricación de mosaicos y baldosas de cemento. Buenos Aires: Nigar, 1958.

CATOIA, Thiago. Ladrilhos e revestimentos hidráulicos de alto desempenho. 2007. $133 \mathrm{f}$. Dissertação (Mestrado) - Escola de Engenharia de São Carlos, São Carlos, 2007.

COSTA, Cacilda Teixeira da. O sonbo e a técnica: a arquitetura de ferro no Brasil. São Paulo: Edusp, 2001.

DARBY, Sue M. The chunk and vesta stoves of Richard Prosser. CIBSE Heritage Group, London, jun. 2014. Disponível em: <https://bit.ly/2IL01SB>. Acesso em: 23 maio 2018.

DURBIN, Lesley. Architectural tiles: conservation and restoration: from the medieval period to the twentieth century. New York: Routledge, 2005. (Butterworth-Heinemann Series in Conservation and Museology).

Nineteenth-century tiles: industrial mass production and construction methods of interior tile schemes in the nineteenth and early twentieth centuries. In: INTERNATIONAL CONGRESS ON CONSTRUCTION HISTORY, 2., 2006, New York. Proceedings... Chicago: CHSA, 2006. p. 989-1005. 
EAMES, Elizabeth S. Medieval tiles: a handbook. London: The British Museum Press, 1968.

English medieval tiles. London: The British Museum Press, 1985.

English tilers: medieval craftsmen. London: The British Museum Press, 1992.

ESQUIEU, Yves. Une histoire du carreau-mosä̈que: la couleur dans la maison. Aix-enProvence: REF.2C, 2013.

FÁBRICA DE MOSAICOS. História do ladrilbo no Brasil: origens do ladrilho hidráulico. Disponível em: <https://bit.ly/2x5BNlN>. Acesso em: 6 set. 2014.

FURNIVAL, William James. Leadless decorative tiles, faience, and mosaic: comprising notes and excerpts on the history, materials, manufacture \& use of ornamental flooring tiles, ceramic mosaic, and decorative tiles and faience : with complete series of recipes for tile-bodies, and for leadless glazes and art-tile enamels. Stone: W. J. Furnival, 1904.

HANS, Van Lemmen. Overview of nineteenth century church tile manufacturers and architects. In: TACS CHURCH CERAMICS CONFERENCE, 25., 2006, Telford. Papers... Manchester: TACS, 2006. p. 1-6.

INSTITUTO DO PATRIMÔNIO HISTÓRICO E ARTÍSTICO NACIONAL. Patrimônio imaterial. 2014. Disponível em: <https://bit.ly/2GMvxzD>. Acesso em: 23 maio 2010.

KRÜGER, Gisela J. Os ladrilhos hidráulicos no patrimônio arquitetônico urbano na zona central de Pelotas In: COLÓQUIO IBERO-AMERICANO, 4., 2014, Belo Horizonte. Anais... Belo Horizonte: UFMG, 2014.

MELO, Carina Mendes dos Santos; RIBEIRO, Rosina Trevisan M. Técnicas construtivas do período eclético no Rio de Janeiro. Revista Brasileira de Arqueometria, Restauração $e$ Conservação, Rio de Janeiro v. 1, n. 3, p. 80-85, 2007.

MESQUITA, José Carlos Vilhena. Opus latericium: termos técnicos de construção civil romana no Algarve. 12 maio 2014. Disponível em: <https://bit.ly/2LpXHU0>. Acesso em: 23 maio 2018.

OFICINA escola de ladrilho hidráulico - Corumbá - MS. 13'13”. Iphangovbr. Youtube. 2011. Disponível em <https://bit.ly/2x4BGa1>. Acesso em: 23 maio 2015.

PESAVENTO, S. J. Exposições universais: espetáculos da modernidade do século XIX. São Paulo: Hucitec, 1997. 
RAINVILLE, César de. O vinhola brazileiro: novo manual pratico do engenheiro, architectyo, pedreiro, carpinteiro, marceneiro e serralheiro. Rio de janeiro: Eduardo \& Henrique Lamaert, 1880.

REIS FILHO, Nestor Goulart. Quadro da arquitetura no Brasil. São Paulo: Perspectiva, 1978.

SEGURADO, João Emílio dos Santos. Materiais de construção. 5. ed. Lisboa: Bertrand, 1959.

SILVA, Gustavo Melo. Estruturas organizacionais de sistemas produtivos artesanais municipais e governança do desenvolvimento local. Revista de Ciências Humanas, Florianópolis, v. 8 , n. 1, p. 23-37, 2008.

SILVA, Svetlana Maria Farias da. Ladrilbos hidráulicos de São Luís: reflexos estéticos de uma época. São Luís: Secretaria de Estado da Cultura; Sesc, 2005.

THE PENNY MAGAZINE. London: Charles Kinght \& Co., 1843.

TRINDADE, Rui André Alves. Revestimentos cerâmicos portugueses: meados do século XIV à primeira metade do século XVI. Lisboa: Colibri, 2007.

Artigo apresentado em 29/06/2016. Aprovado em 19/04/2017 